\title{
Extracting low frequency climate signal from GRACE data
}

O. de Viron ${ }^{1}$, M. Diament ${ }^{1}$, and I. Panet ${ }^{1,2}$

${ }^{1}$ Institut de Physique du Globe de Paris, Paris, France

${ }^{2}$ LAREG, Institut Gographique National, Marne-La-Vallée, France

Received: 27 March 2006 - Accepted: 19 April 2006 - Published: 15 May 2006

Correspondence to: O. de Viron (deviron@ipgp.jussieu.fr)
$1,21-36,2006$

Low frequency signal in GRACE data

O. de Viron et al.

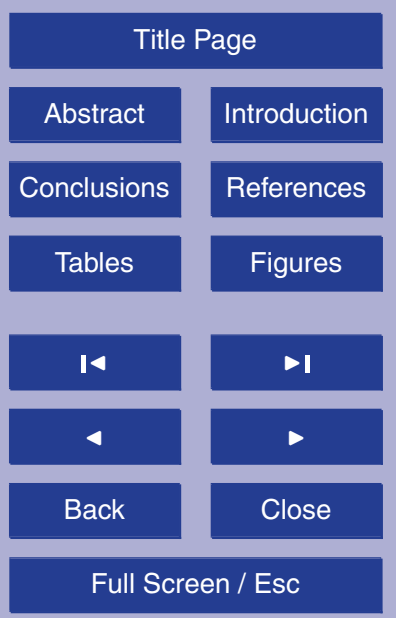

Printer-friendly Version

Interactive Discussion 


\section{Abstract}

For more than three years, the GRACE pair of satellites have been orbiting the Earth, monitoring the time variable mass distribution for scales ranging from regional to global. The GRACE data have been released for a broad scientific community and sets of

5 gravity fields are available. This paper shows that there are evidences at interrannual time scales for the presence of ENSO signal in the data, strongly correlated with the hydrological mass distribution, and also similar to the expected hydrological signature associated with the ENSO cycle. This signal dominates, at global scale, the one associated with geodynamic sources.

\section{Introduction}

The GRACE satellite mission gives access to the temporal variability of the gravity field at global scale. It is now in progress for more than three years, and 22 sphercial harmonics development of the gravitational potential fiels, distributed by the Center for Space Reasearch (CSR, Austin, Texas) from April 2002 to July 2004, are now available for analysis (Tapley et al., 2004). Recently, 10-day solutions combining GRACE, CHAMP, and LAGEOS-1/2 SLR data starting in July 2002 and ending in March 2005 were provided by the French Centre National des Etudes Spatial (CNES, Toulouse, France) (Biancale et al., 2005).

Monitoring the gravity field as a function of time allows to follow the changes in mass distribution within the Earth system. This is of vital importance for studying the climate system, as it is very difficult to monitor, at global scale, the mass redistribution inside the superficial fluid layers, a mandatory task for improving our knowledge of the Earth climate. The GRACE data have already been shown successful in testing hydrological models at the annual (Tapley et al., 2004; Ramillien et al., 2004; Rowlands et al., 2005) and interrannual (Andersen and Hinderer, 2005) periods. Another interest of the GRACE mission is the detection of mass changes due to tectonics (Mikhailov et
$1,21-36,2006$

Low frequency signal in GRACE data

O. de Viron et al.

Title Page

Abstract Introduction

Conclusions

References

Tables

Figures

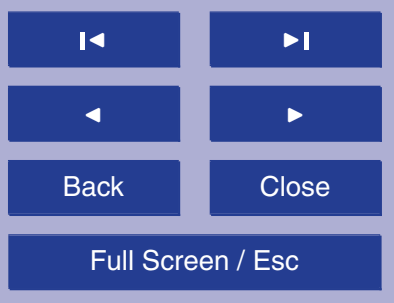

Printer-friendly Version

Interactive Discussion 
al., 2004; Sun and Okubo, 2004). However, such signals are much weaker at global scale than those related to the fluid envelopes. Therefore, it is also necessary to extract the climate signal from the GRACE data prior to any geodynamic analysis.

We analyze GRACE data in order to investigate the low frequency signal and its 5 physical meaning. More specifically, we expect a contribution from the El-Niño Southern Oscillation (ENSO), a global signal in the climate system at interannual timescale. ENSO impact on the hydrology has been reported (e.g., Donders et al., 2005; Foley et al., 2002; Whiting et al., 2004), in various locations. Consequently, we can expect it to be observable in the data as a mode of common variability of the mass distribution

10 at global scale over the continents. The ENSO impact on the ocean is known to be maintly steric and is consequently not expected to be associated with a noticable gravity signal. To search for an ENSO signal in the GRACE data, the Empirical Orthogonal Function (EOF) decomposition is particularly well-suited. First developed for atmosphere science study, this method decomposes a given time varying field in modes 15 of variabilities, in such a way that an important part of the variance can be retrieved from only a few modes, each mode being a time series associated with a geographical distribution. It is thus very efficient at retrieving common variability from noisy signals.

The paper is organized as follows. In Sect. 2, we explain how we prepare the data prior to analysis. In Sect. 3, a very short explanation about the EOF method is given. 20 Section 4 is devoted to the EOF analysis of the available fields, and to the discussion of the results. In Sect. 5, we look for the ENSO signature in the hydrology field over 20 years. Discussion and concluding remarks are given in Sect. 6 .

\section{Data used and their preparation}

Two sets of GRACE data were used in this study: (1) the CSR solution, with 22 monthly

solutions between April 2002 and July 2004, with a missing field in June 2003, and (2) the CNES solution, with 86 monthly solutions, separated by 10 days. As we wanted to have equally spaced data, we linearly interpolate the first dataset to get the missing

Low frequency signal in GRACE data

O. de Viron et al.

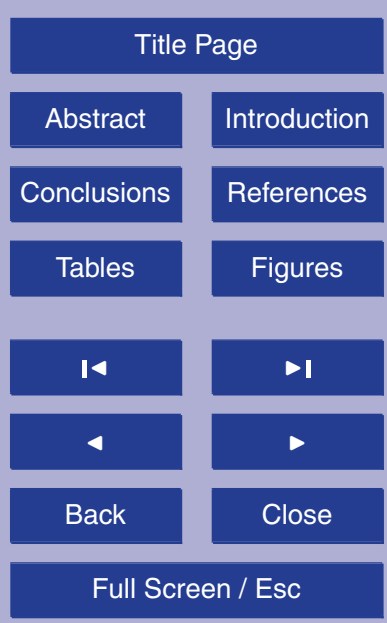

Printer-friendly Version

Interactive Discussion 
data point. The spatial field has been reconstructed on 4-degree by 4-degree grids, from the spherical harmonics development, up to degree 25, with half a Hamming window progressively cutting off from degree 15 .

We then removed a composite annual cycle; at each data point, the average sea5 sonal signal (over the existing 2.3 years of data) was estimated and subtracted, and the results were smoothed with a 4-month window, in order to emphasize the low frequency signal.

From the second dataset, a composite seasonal cycle has been removed, and a 4-month smoothing has been applied on the residuals.

10 We assume that the internannual signal has an hydrological origin, consequently, we finally keep only continent data, as this is where the hydrology signal is, and we used the land dynamics (LaD) hydrology, see Milly and Shmakin (2002), for comparison. The data are available from January 1980 to April 2004, with a 1 degree resolution. For comparison with the GRACE results, we decimated them to the same resolution as 15 our reconstructed field.

To compare with the ENSO, we used the Southern Oscillation Index (SOI, i.e. scaled difference of pressure anomaly between Darwin and Tahiti, see Trenberth, 1984) smoothed with the same 4-month window.

\section{Methods used: the EOF and SVD decompositions}

20 To characterize the spatio-temporal variability of the gravity field, we choose to use the EOF decomposition. This method is explained in details for instance in Preisendorfer (1988). The EOF decomposition represents a space-time data set $\left(x_{i}\left(t_{j}\right), i=1, \ldots, n, j=1 \ldots, m\right)$ in terms of a given number $N$ of variability modes, each of which is a time series $A_{k}(t)$ and a geographical distribution $X_{k}(i)$, with

$x_{i}\left(t_{j}\right)=\sum_{k=1}^{N} A_{k}\left(t_{j}\right) X_{k}(i)$

$1,21-36,2006$

Low frequency signal in GRACE data

O. de Viron et al.

Title Page

Abstract Introduction

Conclusions

References

Tables

Figures

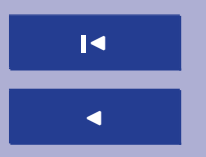

$\Delta \mathbf{I}$

Back $\triangleright$

Close

Full Screen / Esc

Printer-friendly Version

Interactive Discussion 
These modes are obtained from the eigen value decomposition of the covariance matrix $\mathbf{R}=\mathbf{F}^{\mathbf{T}} \mathbf{F}$, with the matrix $F_{i j}=x_{i}\left(t_{j}\right)$. The eigenvalues represent the variance explained by the mode of variability, and the eigenvectors, often called EOF as they are orthogonal, represent the space distribution of the modes. The modes are sorted by 5 decreasing eigenvalue, so that the first mode explains more variance than any other. The time variability associated with each EOF can be retrieved by projecting the matrix $\mathbf{F}$ on the eigen vector.

To retrieve the modes of common variability between two datasets, we used the Singular Value Decomposition (SVD). This method is classically applied when two com10 bined data fields $\left(x_{i}\left(t_{j}\right)\right.$ and $\left.y_{i}\left(t_{j}\right), i=1, \ldots, n, j=1 \ldots, m\right)$ are to be analysed. The method decomposes the signal into time series associated with pairs of spatial patterns. Each pair explains a fraction of the covariance between the two fields. The covariance matrix is then defined as

$$
\mathbf{C}=\mathbf{x}^{\mathbf{T}} \mathbf{y}
$$

\section{EOF decomposition of the GRACE data}

We performed an EOF decomposition on the continent gravity data. The results are shown on Fig. 1. The left panel displays the eigen value as a function of the EOF number. Most of the variance is explained by the first two modes. The two first modes are interannual (see the right panel of Fig. 1). Note that the seasonal cycle has been

A singular value decomposition is then performed on the covariance matrix

$\mathbf{C}=\mathbf{U L V}^{\mathbf{T}}$

The columns of $\mathbf{U}$ are the singular vectors for $x$, and the columns of $\mathbf{V}$ those of $y$. Similarly as what was done for the EOF, each data field is then projected on the singular vectors in order to obtain the time series. removed, otherwise it would be the first mode.
$1,21-36,2006$

Low frequency signal in GRACE data

O. de Viron et al.

Title Page

Abstract Introduction

Conclusions References

Tables Figures

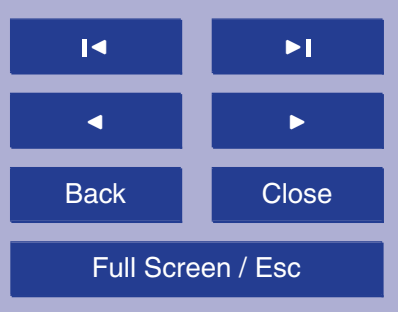

Printer-friendly Version

Interactive Discussion 
We focus on the continental hydrology, and we do not show results for the ocean area. Nevertheless, the time series associated with the first two ocean EOFs are very similar to the one of the continents.

The ENSO is a very important signal in the climate system, and it is global scale. 5 Number of studies have reported impact of the ENSO on the pluviometry and on the hydrology, locally and globally (e.g. Dilley and Heyman, 1995; Cayan et al., 1999; Soden, 2000). Consequently, we expect an ENSO associated signal to be found as a common mode of variability in the mass distribution at the Earth surface, coming from mass variation in hydrology. In Fig. 2, we display the time series of the first EOF and 10 the SOI. The correlation coefficient between the two is equal to 0.89 . To assess the significance of this coefficient, we need to estimate the number of degrees of freedom of the system. This number is classically obtained, for time series, by dividing the length of the signal by the decorrelation time, i.e. the lag for which the auto-correlation drops below $e^{-1}$. We found that there are 3 degrees of freedom in our signal, which 15 makes the computed correlation coefficient significant at more than $98 \%$. This support our hypothesis that the first EOF mode is related to the ENSO cycle. On the left panel, we display the geographical pattern associated with this first mode. We discuss it here bellow, in comparison with the hydrological signal.

A similar analysis has been performed on the larger data set from Biancale et al. 20 (2005), and the results are displayed in Fig. 3. In this case, the ENSO related mode is still present, but appears as the second mode of variability. The first one (not shown) is either a trend or a periodic signal whose period is longer than 5 years.

The mass distribution estimated from the second EOF on the longer dataset (bottom panel of Fig. 3) does not exactly match the first EOF obtained from the shorter dataset 25 (bottom panel of Fig. 2). Nevertheless, some important features appear in both. For instance, except for a positive anomaly in central Europe, the Eurasia mass distribution look fairly similar in the two maps. Considering the correlation between the EOF and SOI time series, it is reasonable to assume that these anomaly maps represent the gravity signal over the continent associated with the ENSO cycle.
1, 21-36, 2006

Low frequency signal in GRACE data

O. de Viron et al.

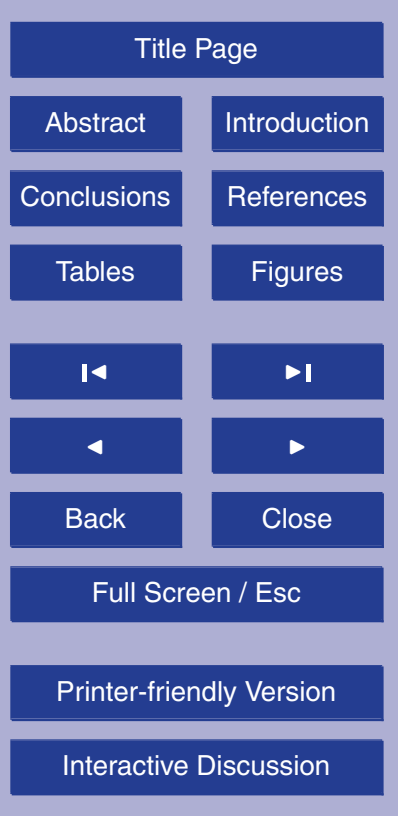




\section{EOF decomposition of the LAD data}

In order to test whether this mass variation is due to a continental hydrology signal, we applied the same analysis to the hydrology data. In Fig. 4, we display the results from the EOF analysis applied to the LAD data whose simulation ends in April 2004. The first 5 EOF time series is well correlated with the SOI. The correlation coefficient is 0.95 , and is significant at the $99 \%$ level, considering that there are again 3 degrees of freedom. The left right panel represents the mass distribution which would be associated with the ENSO.

Whereas the gravity and hydrology maps are not identical, they have some important common features. In particular, the mass anomalies in South America, in Eurasia and in some part of North America are present and in phase on both EOF. In order to have a global measurement of the agreement, we compute a correlation coefficient between the two fields obtained on the same period (Figs. 2 and 4): it is at the level of $33 \%$, but it is difficult to assess the number of degrees of freedom for $2 \mathrm{D}$ fields. As we go to spherical harmonics up to degree 15 before cutting off, we have 136 coefficients, so, we can assume that the 25 degrees of freedom needed to be significant at the $95 \%$ level are there. Comparing with the longer dataset, the geographical patterns of the two EOF decompositions agree even better. Consequently, it seems reasonable, considering that both the time series and the geographical patterns agree, to assume that the signal we obtain by the EOF analysis of the GRACE data is due to an hydrological signal.

To confirm this hypothesis, we computed a Singular Value Decomposition (SVD) of the two set fields. The results we obtained showed that the SVD modes are similar both in time series and in geographical patterns to the one obtained by the EOF.
1, 21-36, 2006

Low frequency signal in GRACE data

O. de Viron et al.

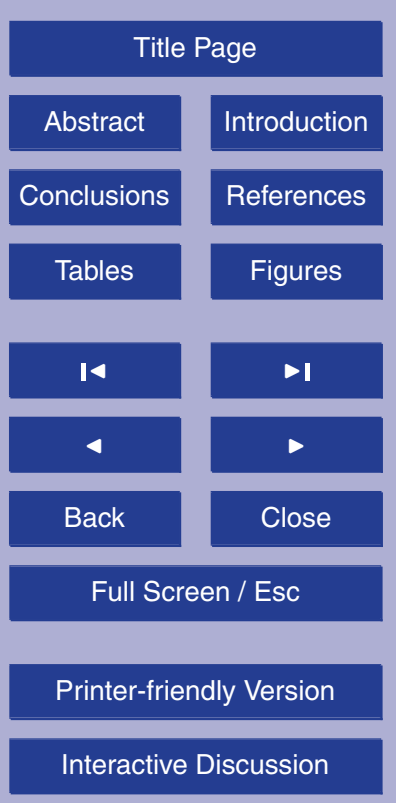




\section{ENSO signature in the LAD hydrology}

We have shown that there are low frequency signals in the GRACE data, and in the LaD hydrology, which are similar both temporally and spatially. We have also shown that the time variability is well correlated with the SOI for the same epoch. Nevertheless, 5 such time limited datasets are quite short to be sure that the extracted signal is ENSO related. We used thus the whole 20 years of $\mathrm{LaD}$ data, to find the hydrology signature of the ENSO. We computed a map of the covariance between the SOI and the hydrology.

The results are displayed on Fig. 5. As shown by comparison with Fig. 4, the geographical patterns are quite similar, and there are an obvious similarities with the anomaly map obtained from the EOF decomposition of the gravity data from Biancale et al. (2005). This strongly supports that the signal we have retrieved from the GRACE data is indeed associated with the ENSO cycle.

\section{Conclusions}

Our aim was to investigate the interannual signal in the GRACE data, and in particular, 15 we thought likely that the ENSO cycle, which is the largest global climate mode, would be present in the GRACE data. Of course, finding a signal which is supposed to be at interannual period with a few year of data is very challenging, but we think we found some convincing evidences that there are long term variability present in the GRACE data, and that an important part of it comes from the hydrological signal associated with the ENSO cycle.

We found 2 modes explaining most of the variance of the low frequency GRACE signal. One of this is associated the SOI. In addition, a mode with a very similar time series and a reasonably similar geographical pattern is also present in the hydrology data. Moreover, the geographical pattern associated with this first mode is typical of the hydrological signature of the El-Niño. More data are necessary to see if this second EOF mode is actually linked or not to those climate signals.
$1,21-36,2006$

Low frequency signal in GRACE data

O. de Viron et al.

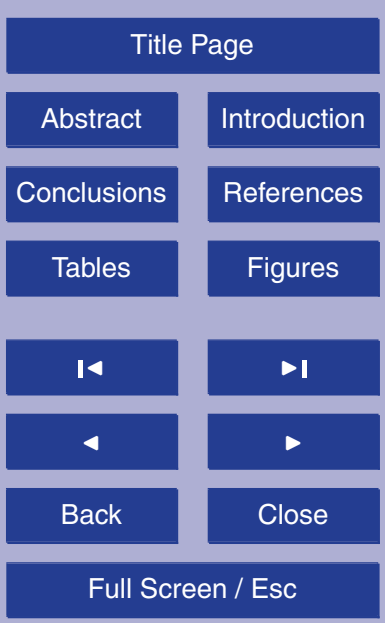

Printer-friendly Version

Interactive Discussion 
To conclude, we have shown that GRACE have captured, during those two years of available data, signal coming from long term variability in the climate system. Extracting the mass variation associated with global scale phenomenon as the ENSO cycle is be of broad interest for many scientists of the Earth sciences. Global time variable 5 gravity missions are unique opportunities to provide a global information on the water distribution, which is necessary to constrain global circulation models of the climate system.

These results also show the efficience of the EOF method to retrieve consistent signal, for instance of climate origin, in the GRACE data. It also shows how this signal 10 can be separated from signal of Earth interior origin, a mandatory task to use GRACE data to study geodynamics.

Acknowledgements. This study was supported by CNES. This paper is the IPGP contribution \#2133.

\section{References}

15 Andersen, O. B. and Hinderer, J.: Global inter-annual changes from GRACE: Early results, Geophys. Res. Lett., 32, L01402, doi:10.2029/2004GL020948, 2005. 22

Biancale, R., Lemoine, J.-M., Balmino, G., Bruinsma, S., Perosanz, F., Marty, J.-C., Loyer, S., and Gégout, P.: 3 years of geoid variations from GRACE and LAGEOS data at 10-day intervals over the period from July 29th, 2002 to March 24th, Data CD, CNES/GRGS product, 2005. 22, 26, 28

Cayan, D. R., Redmond, K. T., and Riddle, L. G.: ENSO and Hydrologic Extremes in the Western United States, J. Climate, 12(9), 2881-2893, 1999. 26

Dayana, U. and Lambb, D.: Global and synoptic-scale weather patterns controlling wet atmospheric deposition over central Europe, Atmos. Environ., 39, 521-533, 2005.

25 Dilley, M. and Heyman, B. N., ENSO and disaster: Droughts, floods and El Niño-Southern Oscillation warm events, Disasters, 19(3), 181-193, 1995. 26

Donders, T. H., Wagner, F., Dilcher, D. L., and Visscher, H.: Mid- to late-Holocene El Niño-
$1,21-36,2006$

Low frequency signal in GRACE data

O. de Viron et al.

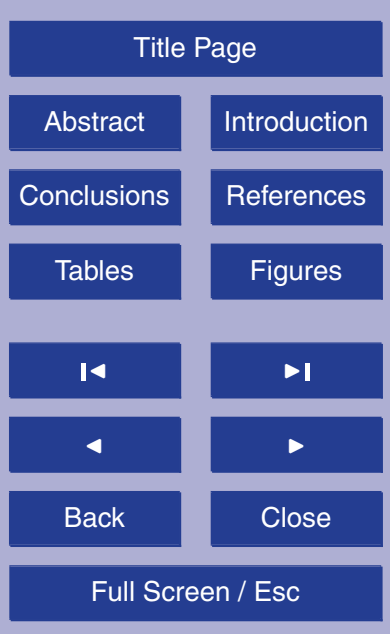

Printer-friendly Version

Interactive Discussion 
Southern Oscillation dynamics reflected in the subtropical terrestrial realm, Proc. Nat. Ac. Sc. of the USA, 102(31), 10904-10 908, 2005. 23

Foley, J. A., Botta, A., Coe, M. T., and Costa, M. H.: El Niño-Southern Oscillation and the climate, ecosystems and rivers of Amazonia, Glob. Biogeochemic. Cycles, 16(4), art. no. 1132, 2002. 23

Han, S., Jekeli, C., and Shum, C. K.: Time-variable aliasing effect of ocean tides, atmosphere, and continental water mass on monthly mean GRACE gravity field, J. Geophys. Res., 109, B04403, doi:10.2029/2003JB002501, 2004.

Mikhailov, V., Tikhotsky, S., Diament, M., Panet, I., and Ballu, V.: Can tectonic processes be recovered from new gravity satellite data?, Earth and Plan. Sci. Lett., 228, 281-297, 2004. 22

Milly, P. C. D. and Shmakin, A. B.: Global modelling of land water and energy balances. Part I: The land dynamics (LaD) model, J. Hydrometeo., 3(3), 283-299, 2002. 24

Mo, K. C. and Livezey, R. E.: Tropical-Extratropical Geopotential Height Teleconnections during 15 the Northern Hemisphere Winter, Mon. Wea. Rev., 114(12), 2488-2515, doi:10.1175/15200493, 1986.

Preisendorfer, R. W.: Principal Component Analyses in Meteorology and Oceanography, Elsevier, 1988. 24

Rowlands, D. D., Luthcke, S. B., Kolsko, S. M., Lemoine, F. G. R, Chinn, D. S., McCarthy, J. J., Cox, C. M., and Anderson, O. B.: Resolving mass flux at high spatial and temporal resolution using GRACE intersatellite measurements, Geophys. Res. Lett., 32, L04310, doi:10.1029/2004GL021908, 2005.

Ramilien, G., Cazenave, A., and Brunau, O.: Global time variations of hydrological signals from GRACE satellite gravimetry, Geophys. J. Int., 158, 813-826, 2004.

Sun W. and Okubo, S.: Coseismic deformations detectable by satellite gravity missions: A case study of Alaska $(1964,2002)$ and Hokkaido (2003) earthquakes in the spectral domain, J. Geophys. Res., 109, B04405, doi:10.1029/2003JB002554, 2004. 23

Soden, B. J.: The Sensitivity of the Tropical Hydrological Cycle to ENSO, J. Climate, 13(3), 538-549, 2000. 26

30 Tapley, B. D., Bettadpur, S., Ries, J. C., Thompson, P. F., and Watkins, M. W.: GRACE Measurements of Mass Variability in the Earth System, Science, 305, 503-503, 2004. 22

Trenberth, K. E.: Signal versus Noise in the Southern Oscillation, Mon. Wea. Rev., 112, 326332, 1984. 24 
Whiting, J. P., Lambert, M. F., Metcalfe, A. V., Adamson, P. T., Franks, S. W., and Kuczera, G.: Relationships between the El-Niño Southern Oscillation and spate flows in southern Africa and Australia, Hydrol. Earth Syst. Sci., 8(6), 1118-1128, 2004. 23
1, 21-36, 2006

\section{Low frequency signal} in GRACE data

O. de Viron et al.

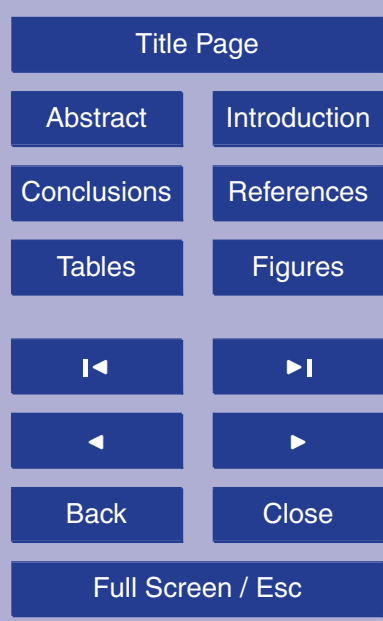

Printer-friendly Version

Interactive Discussion 

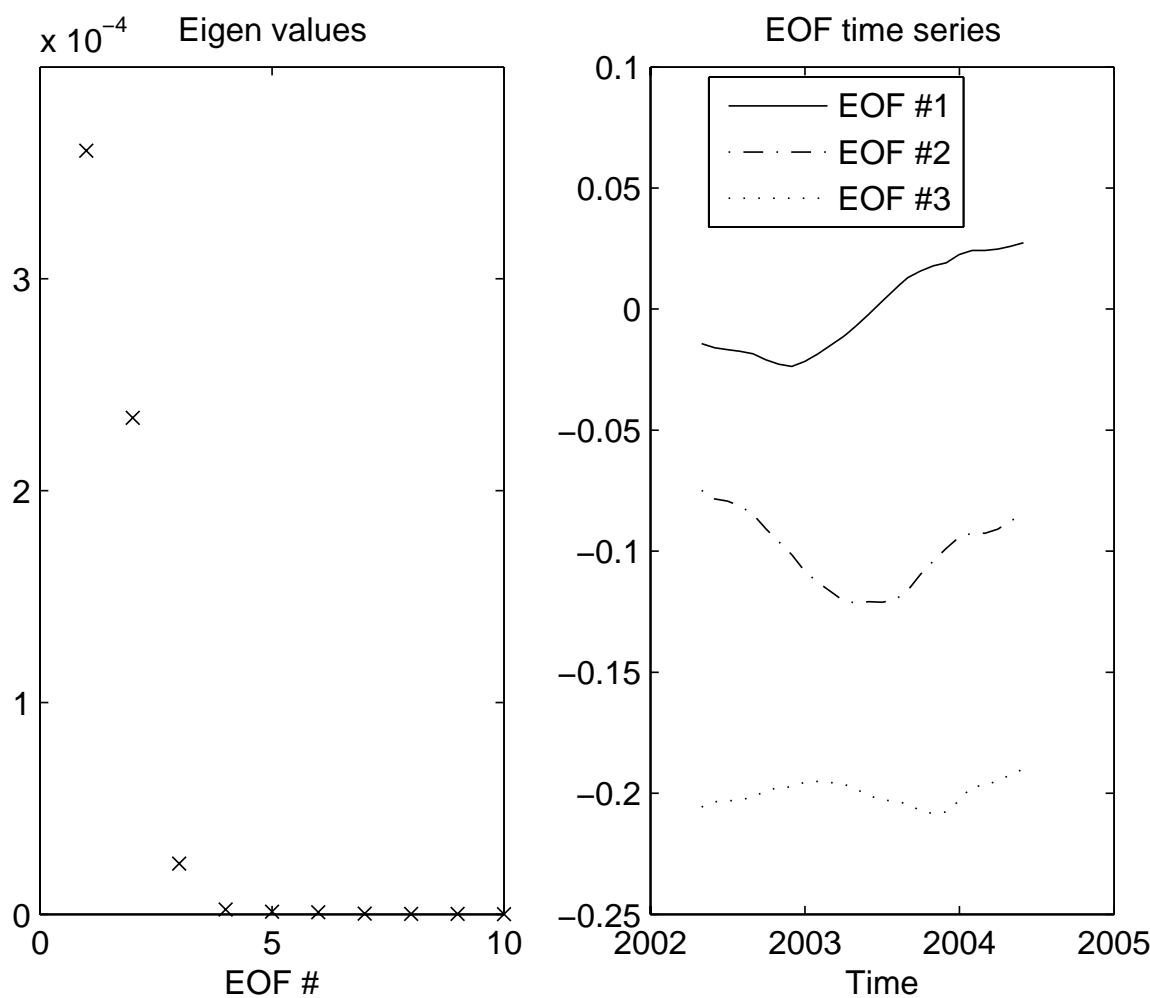

1, 21-36, 2006

Low frequency signal in GRACE data

O. de Viron et al.

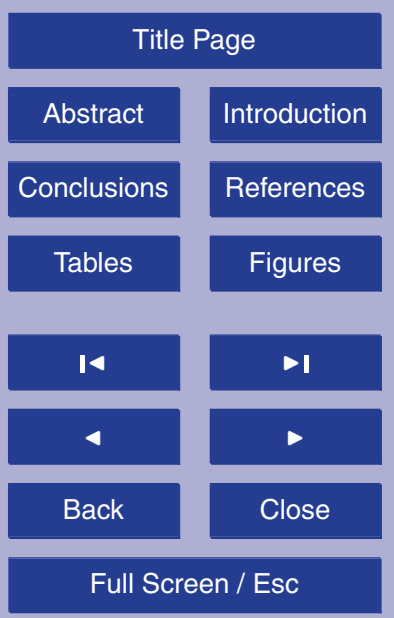

Fig. 1. EOF decompositionof the CSR GRACE data: the left panel shows the eigen values, which are a measure of the variance explained by the EOF, and the right panel shows the time series associated with the EOF, for the three first modes. An arbitrary shift has been added to separate the time series. 
Time series

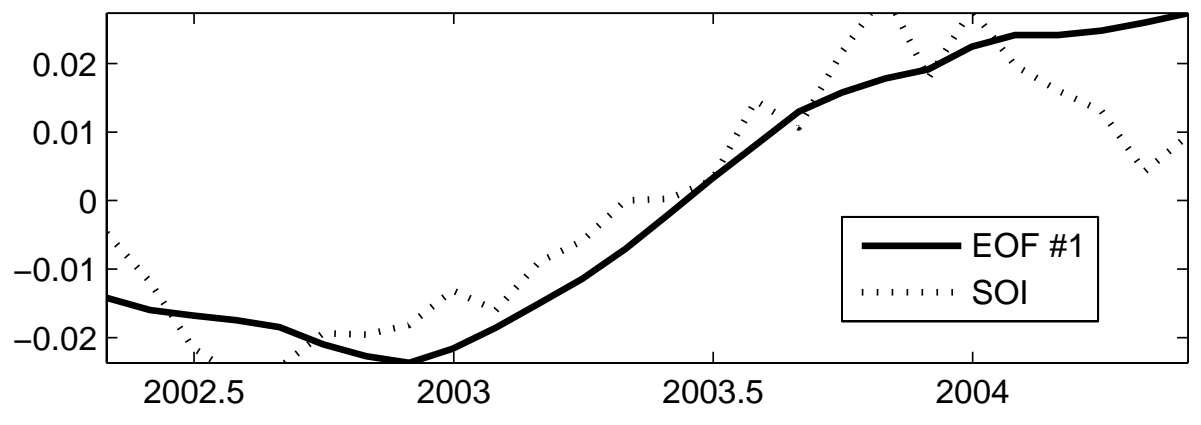

EOF1, continent

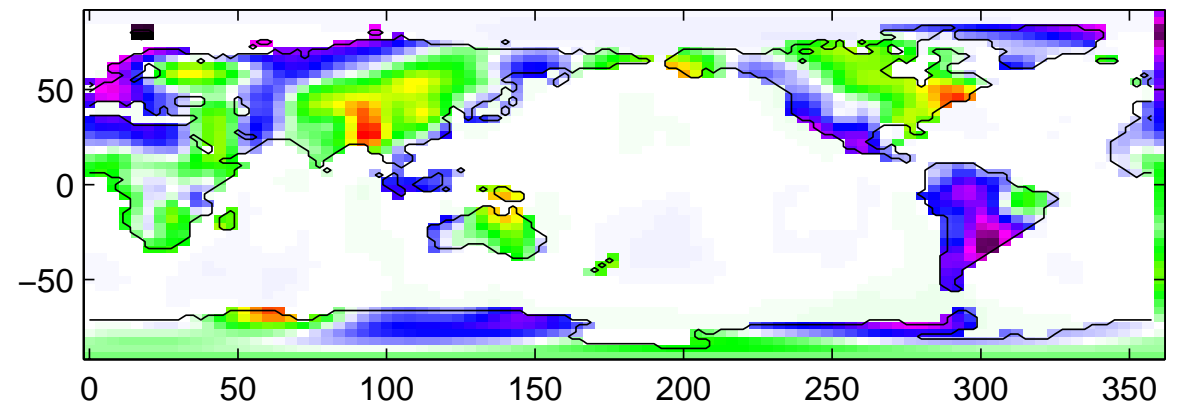

Fig. 2. Top panel: First EOF time series comuputed on the CSR GRACE data, and scaled SOI. Bottom panel: Geographical pattern associated with the first EOF. The results have to be understood as the factor multiplying the time series. Warm colors indicate places where the mass distribution is in phase with the time series, and cold colors indicate places where it is out of phase.
1, 21-36, 2006

\section{Low frequency signal} in GRACE data

O. de Viron et al.

\begin{tabular}{|c|c|}
\hline \multicolumn{2}{|c|}{ Title Page } \\
\hline Abstract & Introduction \\
\hline Conclusions & References \\
\hline Tables & Figures \\
\hline I4 & \\
\hline 4 & $\bullet$ \\
\hline Back & Close \\
\hline Full Screen / Esc
\end{tabular}

Printer-friendly Version

Interactive Discussion 


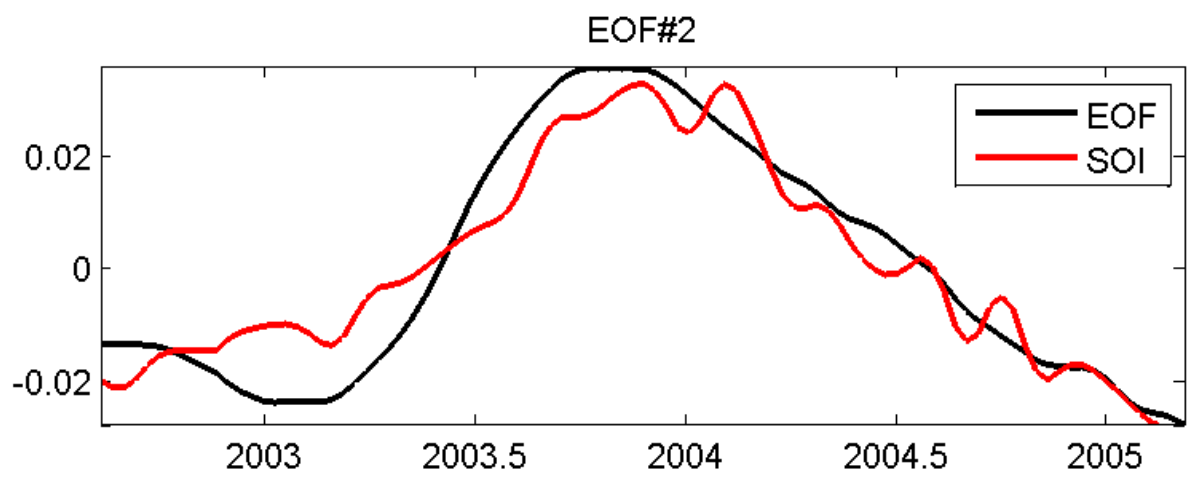

$1,21-36,2006$

\section{Low frequency signal} in GRACE data

O. de Viron et al.

\begin{tabular}{|c|c|}
\hline \multicolumn{2}{|c|}{ Title Page } \\
\hline Abstract & Introduction \\
\hline Conclusions & References \\
\hline Tables & Figures \\
\hline & \\
\hline I & $\bullet$ \\
\hline 4 & $\bullet$ \\
\hline Back & Close \\
\hline Full Screen / Esc
\end{tabular}

Fig. 3. Top panel: Second EOF times series computed from the CNES data and scaled SOI. Bottom panel: Geographical pattern associated with the second EOF. The results have to be understood as the factor multiplying the time series. Warm colors indicate places where the mass distribution is in phase with the time series, and cold colors indicate places where it is out of phase. 

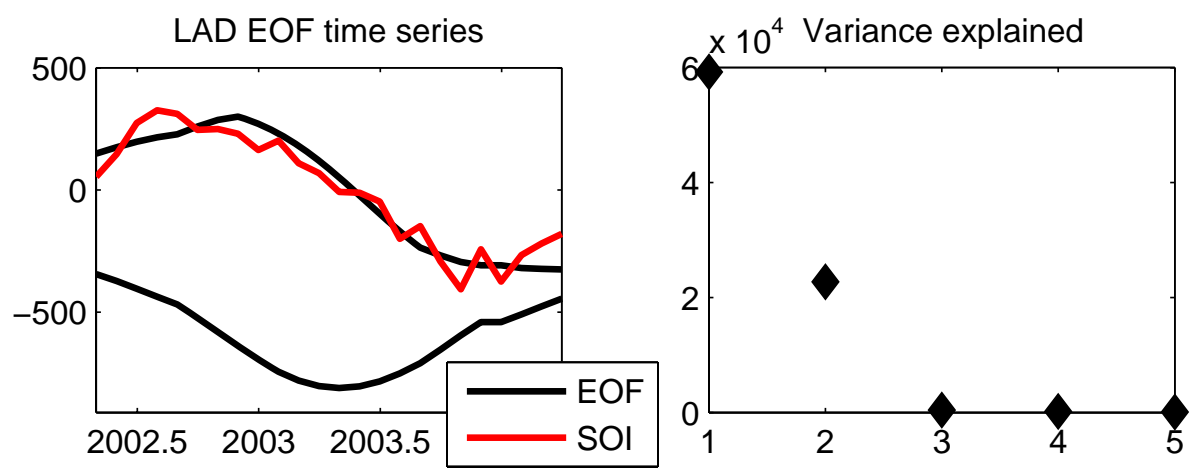

1, 21-36, 2006

Low frequency signal in GRACE data

O. de Viron et al.

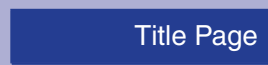

Abstract Introduction

Geographical patern

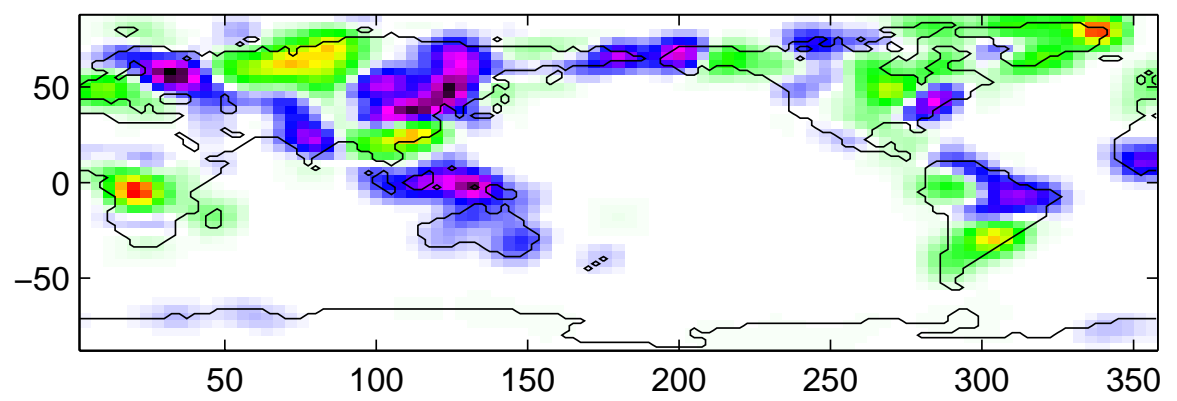

Conclusions

References

Tables

Figures

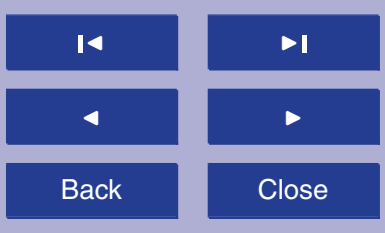

Full Screen / Esc

Fig. 4. Left top panel: First two EOF time series and scaled SOI of the LAD hydrology model. Right top panel: eigen values for the first 5 EOF. Bottom panel: Geographical pattern associated with the first EOF.

Printer-friendly Version

Interactive Discussion 
1, 21-36, 2006

SOI LAD hydro covariance

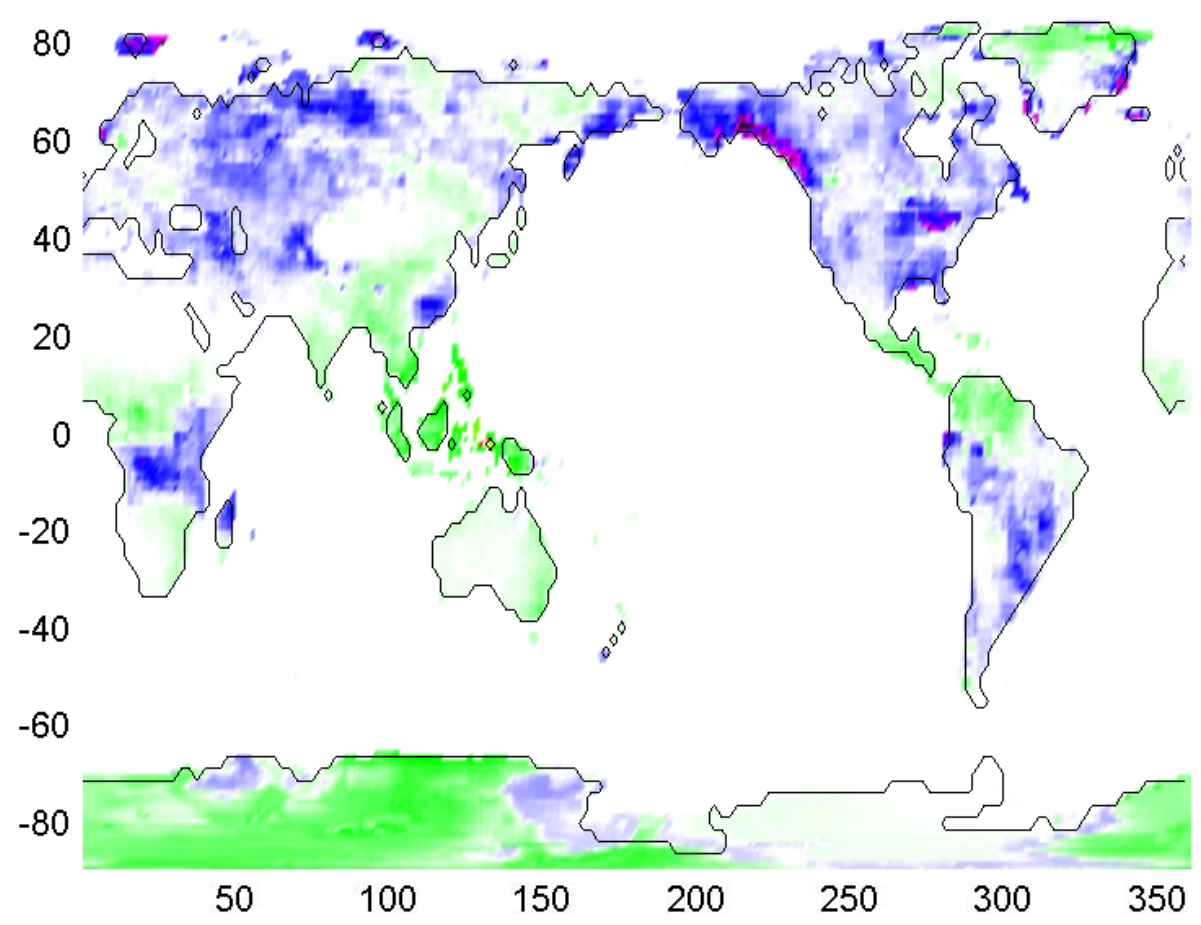

Low frequency signal in GRACE data

O. de Viron et al.

\begin{tabular}{|c|c|}
\hline \multicolumn{2}{|c|}{ Title Page } \\
\hline Abstract & Introduction \\
\hline Conclusions & References \\
\hline Tables & Figures \\
\hline I4 & \\
\hline 4 & $\bullet$ \\
\hline Back & Close \\
\hline Full Screen / Esc
\end{tabular}

Printer-friendly Version

Interactive Discussion 